\title{
Optical Band Gap and Thermal Diffusivity of Polypyrrole-Nanoparticles Decorated Reduced Graphene Oxide Nanocomposite Layer
}

\author{
Amir Reza Sadrolhosseini, ${ }^{1}$ Suraya Abdul Rashid, ${ }^{1}$ A. S. M. Noor, ${ }^{2,3}$ \\ Alireza Kharazmi, ${ }^{4}$ H. N. Lim, ${ }^{5,6}$ and Mohd. Adzir Mahdi ${ }^{2,3}$ \\ ${ }^{1}$ Materials Processing and Technology Laboratory, Nanomaterials and Nanotechnology Group, Institute of Advanced Technology, \\ Universiti Putra Malaysia (UPM), 43400 Serdang, Selangor, Malaysia \\ ${ }^{2}$ Wireless and Photonics Networks Research Center of Excellence (WiPNET), Faculty of Engineering, \\ Universiti Putra Malaysia, 43400 Serdang, Selangor, Malaysia \\ ${ }^{3}$ Department of Computer and Communication Systems Engineering, Faculty of Engineering, \\ Universiti Putra Malaysia, 43400 Serdang, Selangor, Malaysia \\ ${ }^{4}$ School of Chemistry, University of New South Wales, Kensington, NSW 2052, Australia \\ ${ }^{5}$ Department of Chemistry, Faculty of Science, Universiti Putra Malaysia, 43400 Serdang, Selangor, Malaysia \\ ${ }^{6}$ Functional Device Laboratory, Institute of Advanced Technology, Universiti Putra Malaysia, 43400 Serdang, Selangor, Malaysia
}

Correspondence should be addressed to Suraya Abdul Rashid; suraya_ar@upm.edu.my

Received 13 August 2015; Revised 25 November 2015; Accepted 29 November 2015

Academic Editor: Ashok K. Sundramoorthy

Copyright (C) 2016 Amir Reza Sadrolhosseini et al. This is an open access article distributed under the Creative Commons Attribution License, which permits unrestricted use, distribution, and reproduction in any medium, provided the original work is properly cited.

A polypyrrole-nanoparticles reduced graphene oxide nanocomposite layer was prepared using electrochemical method. The prepared samples were characterized using Fourier transform infrared spectroscopy, field emission scanning electron microscopy, and UV-visible spectroscopy. The band gap of nanocomposite layers was calculated from UV-visible spectra and the thermal diffusivity of layers was measured using a photoacoustic technique. As experimental results, the optical band gap was in the range between $3.580 \mathrm{eV}$ and $3.853 \mathrm{eV}$, and thermal diffusivity was increased with increasing the layer thickness from $2.873 \mathrm{~cm}^{2} / \mathrm{s}$ to $12.446 \mathrm{~cm}^{2} / \mathrm{s}$.

\section{Introduction}

Thermal diffusivity is a merit parameter to explain the thermal properties of material. Thermal diffusivity is the ability to transfer thermal energy, and it is a ratio of thermal conductivity $(k)$ to multiplication of heat capacity $(C)$ and density $\left(k /\left(\rho \times C_{p}\right)\right.$, where $\rho$ is density). Thermal conductivity (TC) is an important parameter for evaluating the thermal properties of solid, liquid, and thin film, but the measurement of TC is difficult [1]. Numerous methods such as thermal lens [2], photoflash [3], hotwire [4], and photopyroelectric techniques [5] have been presented to measure the thermal diffusivity properties of materials. Photoacoustic (PA) spectroscopy is a versatile technique used to determine the thermal properties of material such as thermal diffusivity and thermal effusivity. PA is based on the generation of sound in material due to the interaction of light with matter. Hence, it is a nondestructive test (NDT) for evaluating solids and liquid in medicine, biology, and engineering [1].

Conducting polymers such as polyaniline (PANi), polythiophene (PTp), and polypyrrole (PPy) have extended $\pi$ electron conjugation $[6,7]$; hence; this material is considered for scientific and technology applications such as sensors and biosensors. The conducting polymer nanostructure has attracted intense interest due to its large surface-to-volume ratio, short path length for transport of electrical charges, high electrical conductivity, and high electrochemical activity [7-9]. Polypyrrole nanoparticles (PPy-NPs) have particular 
application in sensors and biosensors [10], supercapacitors, and drug delivery. Many methods have been presented for the synthesis of PPy-NPs including swift heavy ion (SHI) [7, 11, 12], monodisperse polymer nanoparticle, chemical oxidation polymerization method, and electrochemical polymerization. The electrodeposition technique is the usual method for preparing the conducting polymer thin film because it can control the thickness of the layer, it is a simple process completed in one step, it can be used in mass production, and it has a low cost [13].

Graphene oxide (GO) is derived from graphene by depicting covalent $\mathrm{C}-\mathrm{O}$ bonds. $\mathrm{GO}$ is two-dimensional and a singleatomic-layered material [14]. It is dispersible in organic and inorganic solutions, such as alcohol and water. GO has application in medicine $[15,16]$ and industry such as composites materials [17], solar cells [18], antibacterial materials [19], and optoelectronic devices [20]. The hydroxyl $\left(\mathrm{OH}^{-}\right)$and epoxy $\left(-\mathrm{COO}^{-}\right)$groups form the main functional group in GO molecules at the basal plane, and carboxyl groups $\left(-\mathrm{COO}^{-}\right)$ were apperceived at the edge of the molecular structure [21, 22]. GO is not appropriate for some electronic applications because it is electrically insulating. In order to enhance the electrical properties, the GO is reduced to graphene-like structure by removing the oxygen-containing group with the recovery of a conjugated structure, that is, reduced graphene oxide (rGO) [23].

The combination of conductive polymer with graphene or graphene oxide has attracted significant attention from material scientists. For example, PPy/rGO has been prepared using chemical methods for adsorption of mercury ion [24]. Polyaniline and polypyrrole with graphene sheets have been fabricated to capture $\mathrm{CO}_{2}[25,26]$. Hence, the combination of conductive polymer and graphene or graphene oxide has application in the environment and biosensors.

In this study, the PPy-NPs/rGO nanocomposite layer was fabricated using the electrodeposition method. The prepared samples were characterized using Fourier transform infrared spectroscopy, field emission scanning electron microscopy (FE-SEM), and UV-visible spectroscopy. Measuring the band gap of nanocomposite layers is important in the optical and thermal properties. Hence, the optical band gap of $\mathrm{PPy}-\mathrm{NPs} / \mathrm{rGO}$ nanocomposite layers was calculated using UV-visible spectra. The thermal diffusivity of PPy-NPs/rGO layers was measured using the PA method to determine the thermal properties of layers.

\section{Materials and Methods}

2.1. Preparation of Polypyrrole-Nanoparticles Decorated rGO Nanocomposite Layer (PPy-NPs/rGO). Graphene oxide (GO) was synthesized using simplified Hummer's method [27], which was employed to prepare PPy-NPs/rGO nanocomposite. GO is reduced during the electrodeposition process [28, 29] and reduction of GO results from enhancing electrical conductivity by restoring the $\pi$-network [30]. The PPy$\mathrm{NPs} / \mathrm{rGO}$ nanocomposite layer was synthesized by electropolymerization from an aqueous solution which contained $0.1 \mathrm{M}$ pyrrole, $1 \mathrm{mg} / \mathrm{mL} \mathrm{GO}, 0.1 \mathrm{M}$ sodium para-toluene sulfonate (NapTS), and $1.0 \mathrm{mM} \mathrm{FeCl}_{3}$. The layer was deposited

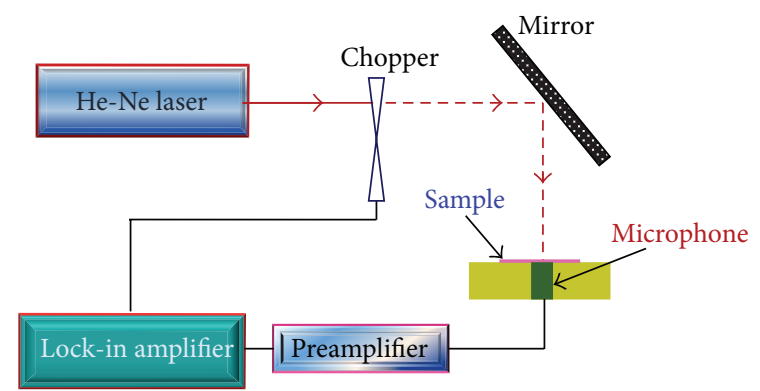

FIgUre 1: Photoacoustic setup contains a He-Ne laser, a mirror, a chopper, a preamplifier, a lock-in amplifier, and a microphone.

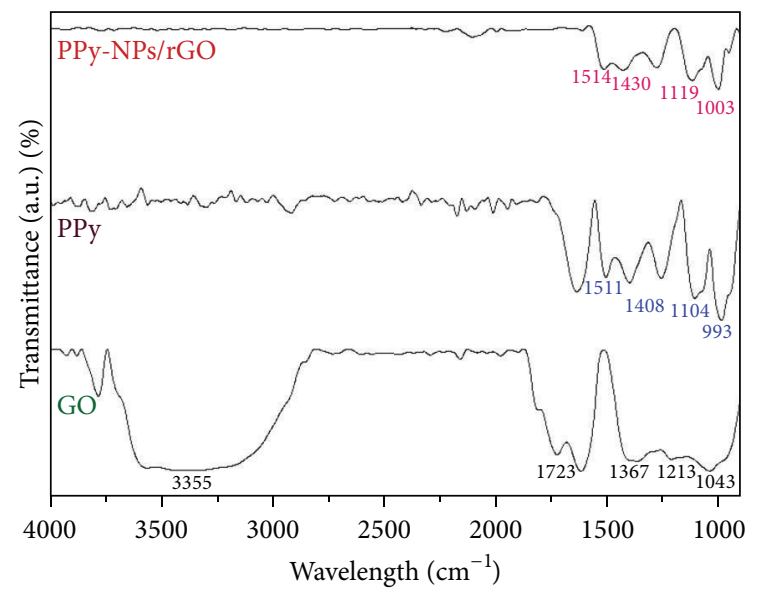

FIgure 2: FT-IR spectrum for GO, PPy, and PPy-NPs/rGO nanocomposite.

using a potentiostat-galvanostat (Elchema model EQCN-502 Faraday cage) at a constant potential of $+0.8 \mathrm{~V}$. A graphite electrode was used as the counter electrode while the working electrode was indium tin oxide (ITO) coated glass, and conductive part of ITO glass was used to deposit the layer. All the potentials were referred to a saturated calomel electrode (SCE). The layers were prepared at different time including $5,10,15,20,25,30,35,40,45,50,55,60,70,80,90100$, and 120 seconds to control the thickness of layers. The samples were prepared with different thicknesses, characterized using the Field Emission Scanning Electron Microscope (FE-SEM, Hitachi, SU8000 Series) and Fourier transform infrared spectroscopy (FT-IR, Spectrum 100, Perkin Elmer), and the thickness of layers was obtained using high surface profilometer (Ambios Technology XP-200) with a limitation of about $\pm 10 \mathrm{~nm}$. The PA method was utilized to measure the thermal diffusivity of samples.

2.2. Photoacoustic Setup. Figure 1 shows the photoacoustic setup containing a He-Ne laser ( $75 \mathrm{~mW}, 632.8 \mathrm{~nm}$ ), a chopper, a mirror, a microphone with holder, a preamplifier, and a lock-in amplifier [31]. The chopper frequency was shifted from $21 \mathrm{~Hz}$ to $236 \mathrm{~Hz}$ controlled by a computer. The sample was located on a microphone, and the laser beam irradiated the film vertically. To measure the thermal diffusivity of 

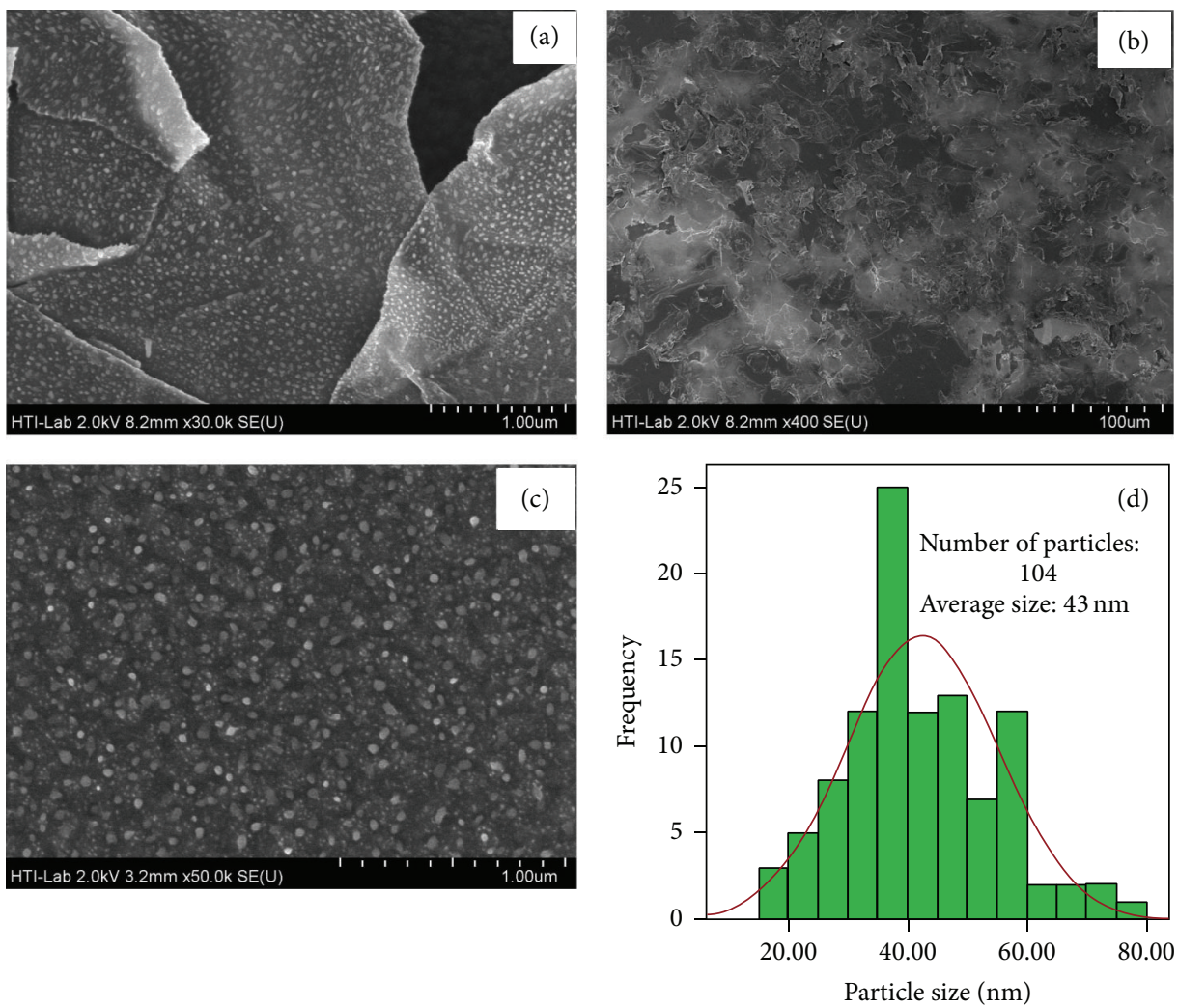

Figure 3: (a) PPy-NPs were attached to rGO; (b) PPy-NPs/rGO nanocomposite file; (c) distribution of PPy-NPs on basal planes; (d) analysis of (c).

the PPy-NPs/rGO nanocomposite layers, the photoacoustic signals were registered using an electret microphone, connected to a preamplifier and a lock-in amplifier (Figure 1). The phase and amplitude of the signals were a function of a light beam modulation frequency, and the electret microphone registered the amplitude of the signals. Measurements were carried out at room temperature for ITO glass Si wafer and PPy-NPs/rGO nanocomposite layers.

\section{Results and Discussion}

Figure 2 depicts the FT-IR spectrum for authentication of bonding the PPy-NPs and rGO. GO contains a wide range of oxygen functional groups on its basal planes and the edges of the GO sheets [32]. The spectra of GO in Figure 2 demonstrate the presence of $\mathrm{C}-\mathrm{O}, \mathrm{COOH}$, and $\mathrm{COC} / \mathrm{C}-\mathrm{OH}$ in $1723 \mathrm{~cm}^{-1}$ and in the range of $1400-1000 \mathrm{~cm}^{-1}$ in addition to a broad and intense peak at $3355 \mathrm{~cm}^{-1}$ that corresponds to the $\mathrm{OH}$ peak. From the spectra of PPy-NPs/rGO, the peaks at $1514,1430,1119$, and $1003 \mathrm{~cm}^{-1}$ correspond to the N-H bend, aromatic ring stretching, C-N stretching, and N-H out-ofplane bending of PPy, showing the presence of PPy in the nanocomposite film $[32,33]$. Moreover, the absorption bands related to oxygen-containing groups on GO diminished, indicating a high degree of reduction of GO in the PPy matrix. On the other hand, the interaction of PPy-NPs and rGO is electrostatic because the negatively charged rGO, obtained from the electrostatic repulsive interaction of adjacent $\mathrm{rGO}$, is attracted to the positively charged PPy [34].

Figure 3 shows the FE-SEM image of the PPy-NPs/rGO nanocomposite layer. Figures 3(a) and 3(b) illustrate the PPyNPs formed on basal planes of rGO. Figure 3(c) depicts the distribution and particle size of PPy-NPs in nanocomposite; it was analysed using image tools (UTHSCA, Ver. 3) software and particle size was about $43 \mathrm{~nm}$. The distribution of nanoparticles was uniformly embedded on the surface of rGO, and the rGO sheet remained spread on the substrate. Consequently, the electrodeposition method is a merit technique for preparing the uniform PPy-NPs/rGO nanocomposite layer.

Figure 4 illuminates the variation in thickness resulting from increased deposition time, and the thickness of nanocomposite layers was shifted from $6.5 \mathrm{~nm}$ to $618.6 \mathrm{~nm}$, controlled with electrodeposition time. Figures 5(a) and 5(b) show the UV-visible spectra of PPy-NPs/rGO nanocomposite layers. The experiments were carried out at room temperature, and the reference was ITO glass. The absorbance increased by increasing the thickness of the layer. The peaks $463 \mathrm{~nm}$ and $281 \mathrm{~nm}$ are related to the $\pi-\pi^{*}$ transition band of PPy-NPs and rGO, consistent with the literature [35]. The blue shift does not appear in the absorption peak due to PPyNPs; hence, the particle size was held constant with increased thickness of the layer. 


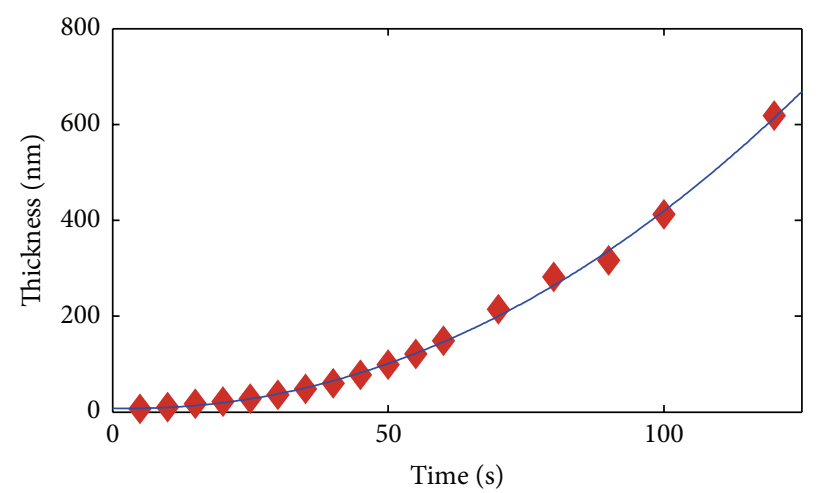

Experimental data

$d=a x^{3}+b x^{2}+c x+d$

$a=0.000025$

$b=0.04133$

$c=-0.2659$

$d=8.0729$

FIGURE 4: Variation of thickness with the deposition time.

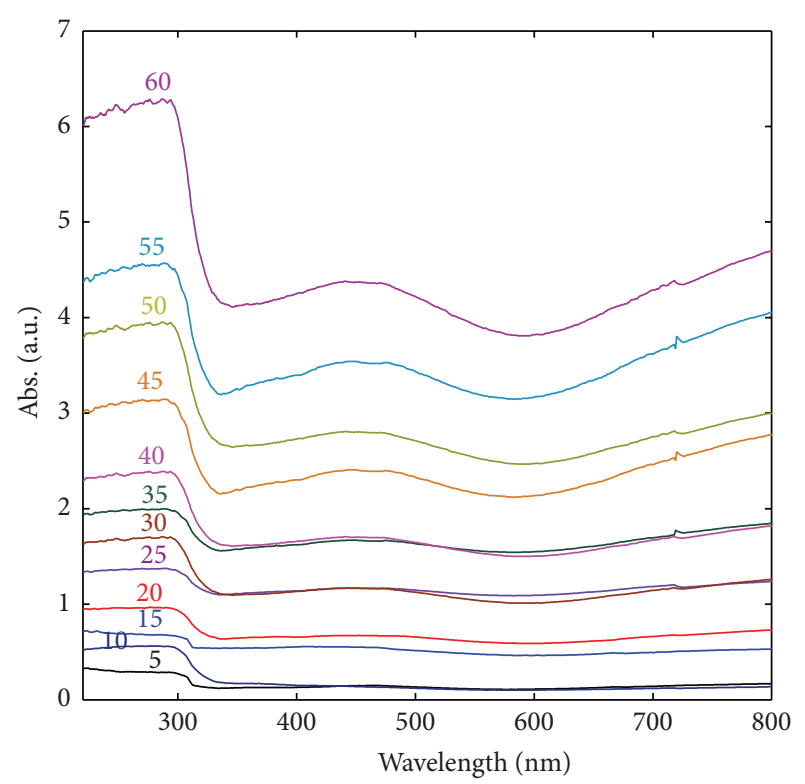

(a)

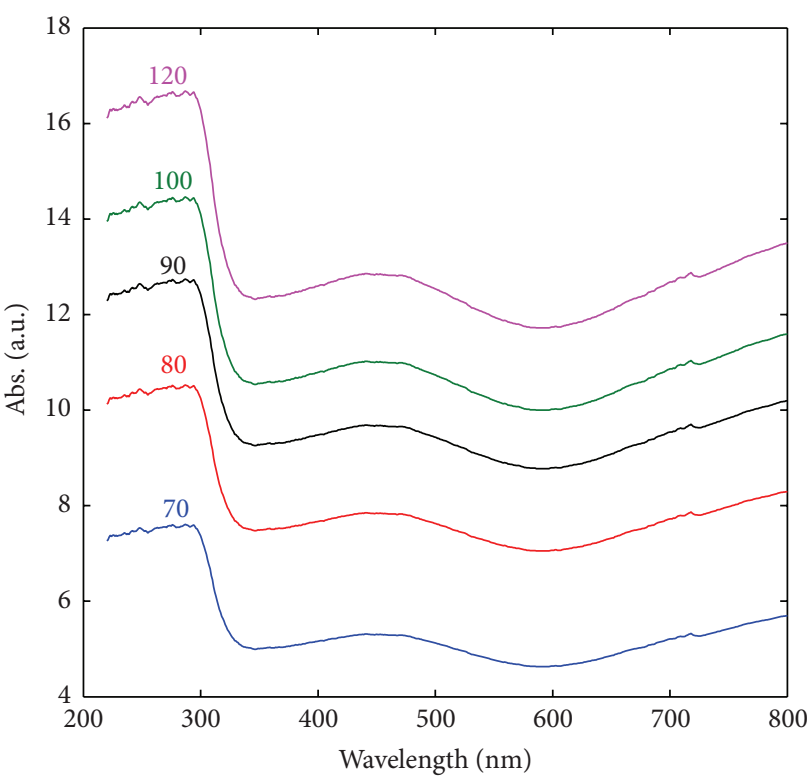

(b)

FIgURE 5: UV-visible spectra of PPy-NPs/rGO nanocomposite.

The energy band gap $\left(E_{g}\right)$ of PPy-NPs/rGO was obtained with absorption spectra. To calculate the energy band gap, the Tauc relation was used [36]:

$$
[\alpha h \nu]^{2}=K\left(h v-E_{g}\right)^{n},
$$

where $h v$ is the photon energy, $K$ is the constant, $n=1$ for direct band gap, and $\alpha$ is the absorption coefficient. The absorption coefficient is a function of wavelength and thickness $(d)$ as follows [37]:

$$
\alpha(\lambda)=\frac{2.303}{d} A(\lambda) .
$$

The plot of $[\alpha h \nu]^{2}$ versus photon energy was used to calculate the optical band gap. Figure 6 depicts the variation of $[\alpha h v]^{2}$ versus $h v$ for the PPy-NPs/rGO nanocomposite layer with different thickness. The optical band gaps were obtained through extrapolation of the straight portion of plot $\left([\alpha h v]^{2}=0\right)[38]$. Figure 6(a) shows the variation of $[\alpha h \nu]^{2}$ versus $h v$ for the PPy-NPs/rGO nanocomposite layer with different thickness controlled with electrodeposition time, extrapolation of the straight plot was done for the PPy$\mathrm{NPs} / \mathrm{rGO}$ nanocomposite layers, and the optical band gap was calculated. Figure 6(b) illuminates the extrapolation of plot for $5 \mathrm{~s}$ and $120 \mathrm{~s}$ and the optical band gap $\left(E_{g}\right)$ was in range 3.580 to $3.853 \mathrm{eV}$. The results are shown sorted in Table 1.

Figures 7 and 8 illustrate the PA signal related to the Si wafer, ITO glass, and PPy-NPs/rGO nanocomposite layers 


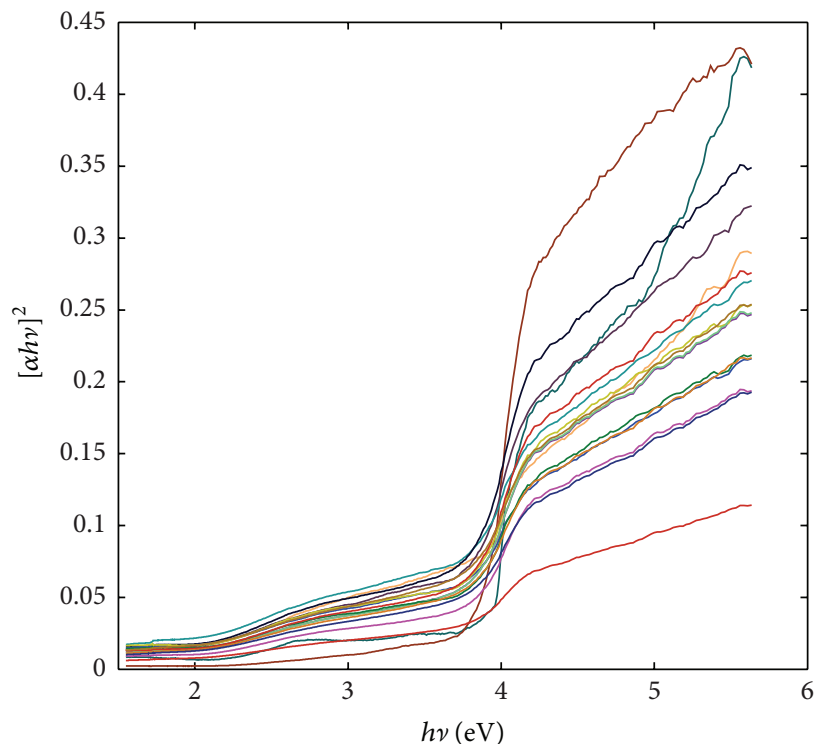

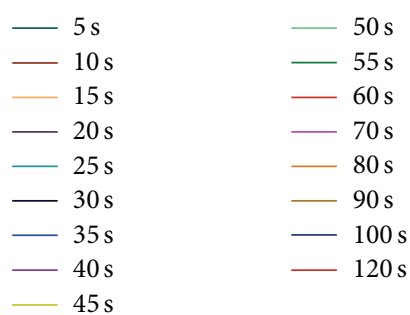

(a)

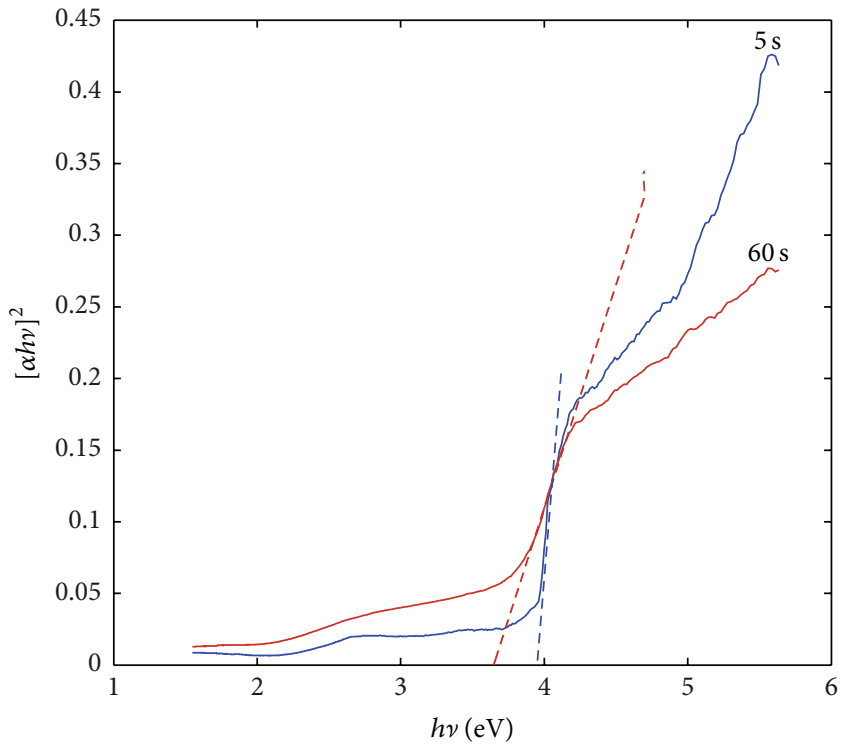

(b)

Figure 6: (a) Variation of the PPy-NPs/rGO nanocomposite layer with different thickness; (b) calculation of energy band gap for $5 \mathrm{~s}$ and $120 \mathrm{~s}$.
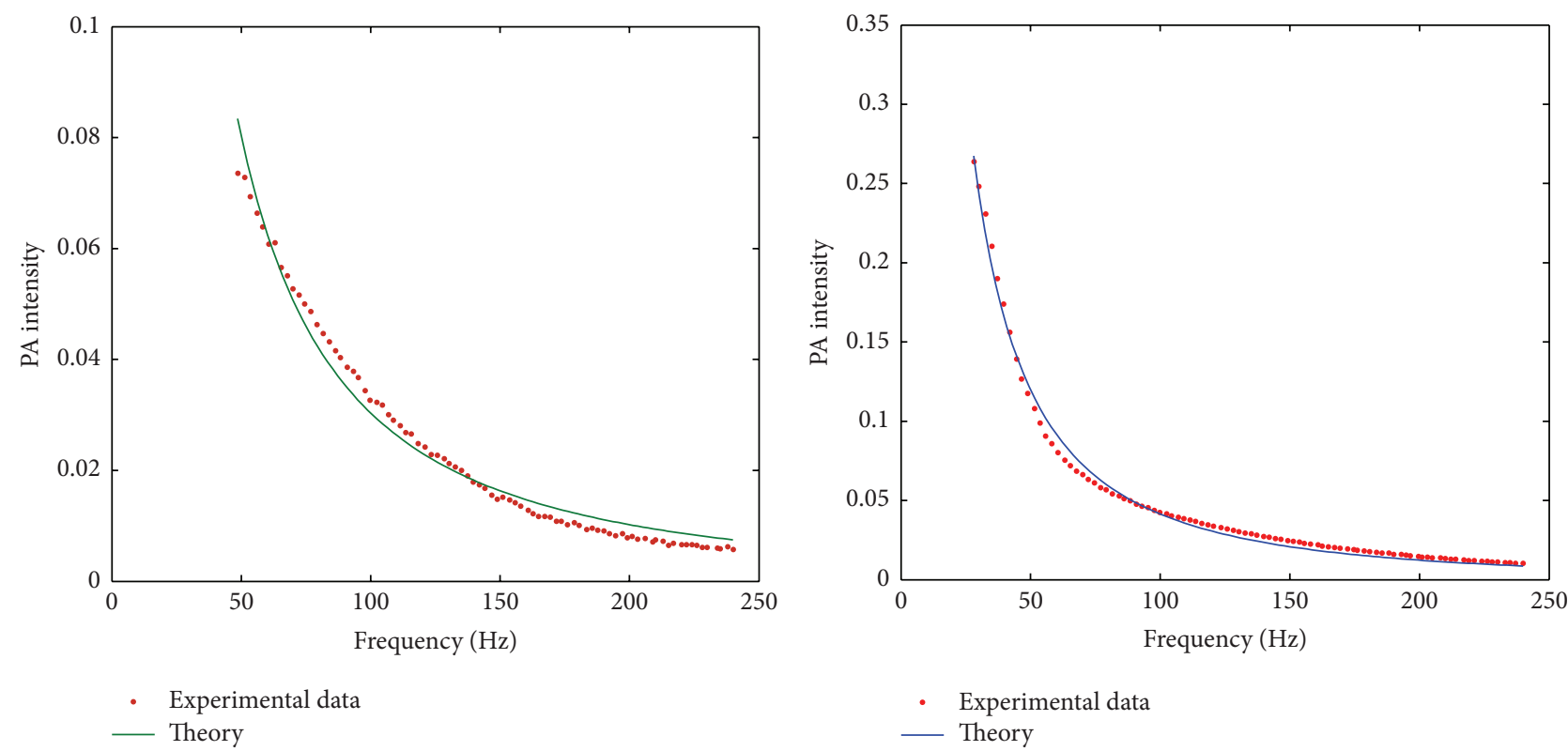

(a)

(b)

FIGURE 7: PA signal for measurement of thermal diffusivity of (a) Si, (b) ITO glass. 

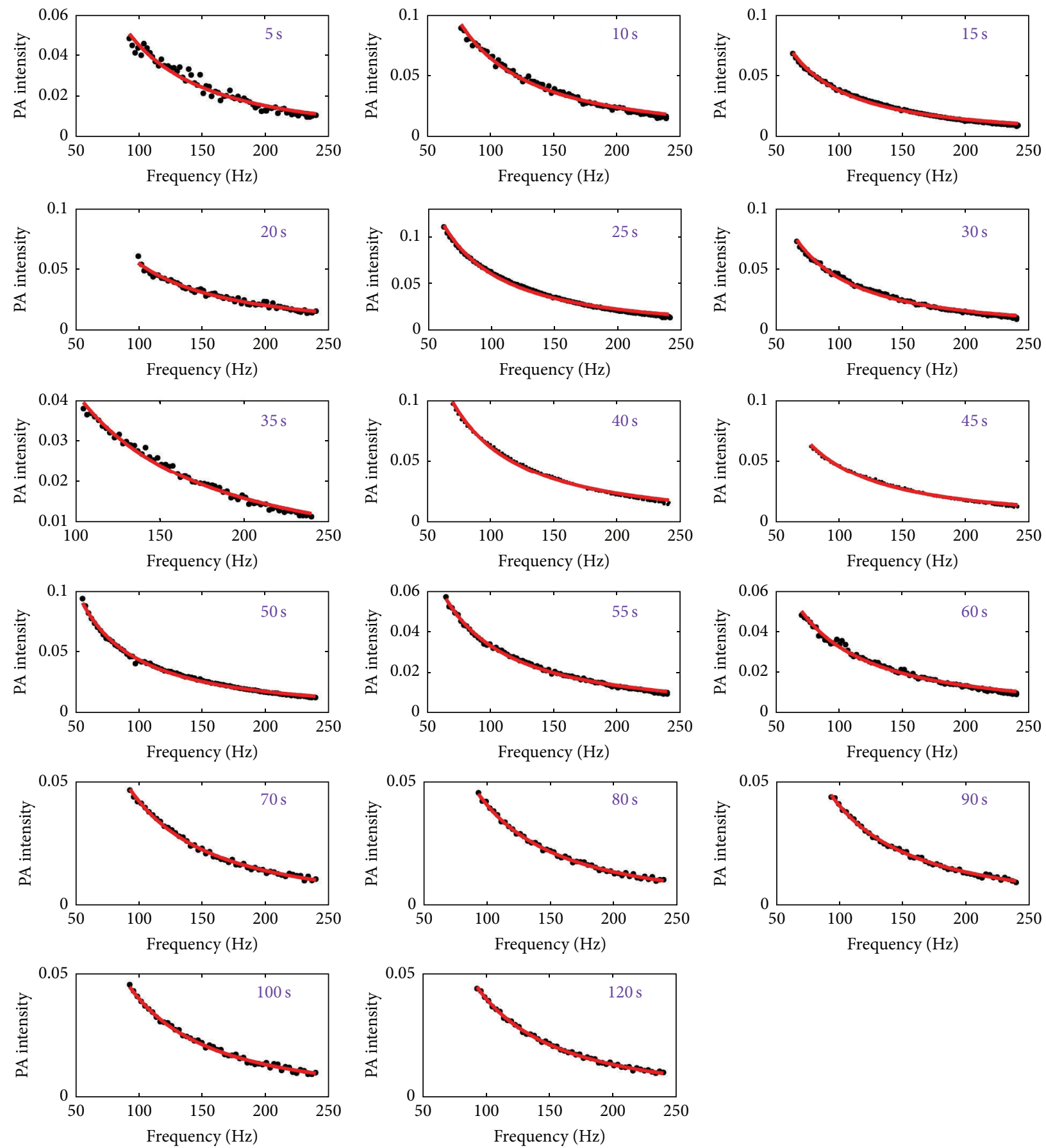

FIGURE 8: Photoacoustic signals for measurement of thermal diffusivity of PPy-NPs/rGO nanocomposite layers with different thickness, controlled with deposition time from 5 to 120 minutes.

to calibrate and measure the thermal diffusivity. To obtain the thermal diffusivity of layers, the amplitude $(S)$ of the photoacoustic signals was registered by a different chopping frequency $(f)$. In accordance with photoacoustic theory, the amplitude of photoacoustic signals decreased with variation in frequency, as follows $[6,39-41]$ :

$$
S=\frac{a}{f} \exp \left(-b f^{1 / 2}\right), \quad b=\sqrt{\frac{\pi l_{S}^{2}}{\alpha_{S}}},
$$

where $\alpha_{S}$ and $l_{S}$ are the thermal diffusivity and thickness of the layer. Hence, in Figures 7 and 8, the solid line demonstrates the theory as fitting the experimental data. The amplitude of signals decreased with increments of chopper frequency. The dotted points are experimental results and solid lines are theoretical and fitted to experimental data. To calibrate the photoacoustic setup, the thermal diffusivity of the $\mathrm{Si}$ wafer was measured. The PA signal presented in Figure 7(a) is equivalent to $0.9296 \mathrm{~cm}^{2} / \mathrm{s}$ consistent with the literature. As 
TABLE 1: The values of thermal diffusivity and band gap of ITO glass and PPy-NPs/rGO nanocomposite layers.

\begin{tabular}{lccc}
\hline Sample & $\alpha\left(\mathrm{cm}^{2} / \mathrm{s}\right)$ & Thickness of sample & $E_{g}$ \\
\hline ITO & 1.79 & $0.095 \mathrm{~cm}$ & \\
$5 \mathrm{~s}$ & 2.873 & $6.5 \mathrm{~nm}$ & 3.853 \\
$10 \mathrm{~s}$ & 4.753 & $10.3 \mathrm{~nm}$ & 3.834 \\
$15 \mathrm{~s}$ & 5.078 & $17.2 \mathrm{~nm}$ & 3.603 \\
$20 \mathrm{~s}$ & 5.087 & $21.6 \mathrm{~nm}$ & 3.645 \\
$25 \mathrm{~s}$ & 5.096 & $28.3 \mathrm{~nm}$ & 3.505 \\
$30 \mathrm{~s}$ & 5.199 & $35.7 \mathrm{~nm}$ & 3.658 \\
$35 \mathrm{~s}$ & 5.364 & $48.4 \mathrm{~nm}$ & 3.523 \\
$40 \mathrm{~s}$ & 5.489 & $59.8 \mathrm{~nm}$ & 3.628 \\
$45 \mathrm{~s}$ & 6.872 & $77.4 \mathrm{~nm}$ & 3.618 \\
$50 \mathrm{~s}$ & 8.256 & $98.6 \mathrm{~nm}$ & 3.631 \\
$55 \mathrm{~s}$ & 9.672 & $121.3 \mathrm{~nm}$ & 3.602 \\
$60 \mathrm{~s}$ & 10.392 & $148.4 \mathrm{~nm}$ & 3.647 \\
$70 \mathrm{~s}$ & 11.42 & $214.2 \mathrm{~nm}$ & 3.634 \\
$80 \mathrm{~s}$ & 11.972 & $282.3 \mathrm{~nm}$ & 3.528 \\
$90 \mathrm{~s}$ & 12.251 & $316.5 \mathrm{~nm}$ & 3.509 \\
$100 \mathrm{~s}$ & 12.453 & $412.4 \mathrm{~nm}$ & 3.596 \\
$120 \mathrm{~s}$ & 12.446 & $618.6 \mathrm{~nm}$ & 3.580 \\
\hline
\end{tabular}

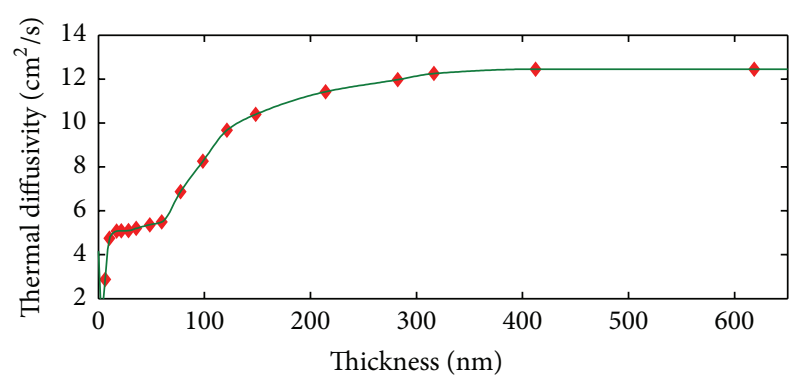

FIgURE 9: Variation of thermal diffusivity with thickness of PPyNPs/rGO nanocomposite layer.

a result, the thermal diffusivity of ITO glass is $1.79 \mathrm{~cm}^{2} / \mathrm{s}$ and the thermal diffusivity of nanocomposite layers shifted from $2.873 \mathrm{~cm}^{2} / \mathrm{s}$ to $12.446 \mathrm{~cm}^{2} / \mathrm{s}$ as seen in Table 1 .

Figure 9 shows the variation in thermal diffusivity versus thickness of layers. The thermal diffusivity of layers increased with increments of layer thickness. Thermal diffusivity of the samples explains transient heat scattering through the layer. When the thickness of the layer increased, the population of reduced graphene oxide sheet increased, and the layer absorbs the higher intensity of light (Figure 5). Hence, the number of phonons, which contribute to heat conductivity, increases and the phonon mean path decreases. Consequently, the thermal diffusivity increased with an increase in the thickness of the PPy-NPs/rGO nanocomposite layer.

\section{Conclusions}

A polypyrrole-nanoparticles reduced graphene oxide nanocomposite layer was deposited on conductive side of ITO glass using the electrochemical method. The PPy-NPs were distributed uniformly on the surface of rGO, and the rGO sheet remained spread on the substrate. The thickness of the layer shifted from $6.5 \mathrm{~nm}$ to $618.6 \mathrm{~nm}$, and the particle size obtained from analysis of the FE-SEM image was about $43 \mathrm{~nm}$. The optical band gap of the nanocomposite layers was in the range of $3.580 \mathrm{eV}$ to $3.853 \mathrm{eV}$. The thermal diffusivity of the nanocomposite layers was increased with increments of layer thickness from $2.873 \mathrm{~cm}^{2} / \mathrm{s}$ to $12.446 \mathrm{~cm}^{2} / \mathrm{s}$.

\section{Conflict of Interests}

The authors declare that there is no conflict of interests regarding the publication of this paper.

\section{Acknowledgment}

The authors acknowledge Universiti Putra Malaysia for the fund from the Research University Grant Scheme (Putra Grant, Vote 941300) and the postdoctoral fellowship under the Institute of Advanced Technology (ITMA).

\section{References}

[1] W. Hu, C. Peng, W. Luo et al., "Graphene-based antibacterial paper," ACS Nano, vol. 4, no. 7, pp. 4317-4323, 2010.

[2] M. Choe, C.-Y. Cho, J.-P. Shim et al., "Au nanoparticle-decorated graphene electrodes for GaN-based optoelectronic devices," Applied Physics Letters, vol. 101, no. 3, Article ID 031115, 2012.

[3] G. Eda and M. Chhowalla, "Chemically derived graphene oxide: towards large-area thin-film electronics and optoelectronics," Advanced Materials, vol. 22, no. 22, pp. 2392-2415, 2010.

[4] D. S. Sutar, G. Singh, and V. D. Botcha, "Electronic structure of graphene oxide and reduced graphene oxide monolayers," Applied Physics Letters, vol. 101, no. 10, Article ID 103103, 2012.

[5] H. Liu, L. Zhang, Y. Guo et al., "Reduction of graphene oxide to highly conductive graphene by Lawesson's reagent and its electrical applications," Journal of Materials Chemistry C, vol. 1, no. 18, pp. 3104-3109, 2013.

[6] E. Ramachandran, P. Raji, K. Ramachandran, and S. Natarajan, "Photoacoustic study of the thermal properties of calcium carbonate-the major constituent of pancreatic calculi," Crystal Research and Technology, vol. 41, no. 1, pp. 64-67, 2006.

[7] S. Bialkowski, Photothermal Spectroscopy Methods for Chemical Analysis, vol. 134 of Chemical Analysis, Wiley, New York, NY, USA, 1996, Edited by J. D. Winefordner.

[8] S. Soltaninejad, M. S. Husin, A. R. Sadrolhosseini et al., “Thermal diffusivity measurement of Au nanofluids of very low concentration by using photoflash technique," Measurement, vol. 46, no. 10, pp. 4321-4326, 2013.

[9] H. M. Roder, "Transient hot wire thermal conductivity apparatus for fluids," Journal of Research of the National Bureau of Standards, vol. 86, pp. 457-493, 1981.

[10] A. R. Sadrolhosseini, M. M. Moksin, H. L. L. Nang, M. Norozi, M. M. W. Yunus, and A. Zakaria, "Physical properties of normal grade biodiesel and winter grade biodiesel," International Journal of Molecular Sciences, vol. 12, no. 4, pp. 2100-2111, 2011.

[11] Y. Zhen, H. W. C. Postma, L. Balents, and C. Dekker, "Carbon nanotube intramolecular junctions," Nature, vol. 402, no. 6759, pp. 273-276, 1999.

[12] J. Hazarika and A. Kumar, " $160 \mathrm{MeV} \mathrm{Ni}^{12+}$ ion irradiation effects on the structural, optical and electrical properties of spherical 
polypyrrole nanoparticles," Nuclear Instruments and Methods in Physics Research B, vol. 318, pp. 269-275, 2014.

[13] C. M. Li, C. Q. Sun, W. Chen, and L. Pan, "Electrochemical thin film deposition of polypyrrole on different substrates," Surface \& Coatings Technology, vol. 198, no. 1-3, pp. 474-477, 2005.

[14] J. X. Huang, S. Virji, B. H. Weiller, and R. B. Kaner, "Polyaniline nanofibers: facile synthesis and chemical sensors," Journal of the American Chemical Society, vol. 125, no. 2, pp. 314-315, 2003.

[15] N.-R. Chiou, C.-M. Lu, J.-J. Guan, L. J. Lee, and A. J. Epstein, "Growth and alignment of polyaniline nanofibres with superhydrophobic, superhydrophilic and other properties," Nature Nanotechnology, vol. 2, no. 6, pp. 354-357, 2007.

[16] W. Yoon, S. H. Lee, O. S. Kwon et al., "Polypyrrole nanotubes conjugated with human olfactory receptors: high-performance transducers for FET-type bioelectronic noses," Angewandte Chemie-International Edition, vol. 48, no. 15, pp. 2755-2758, 2009.

[17] E. Balanzat, S. Bouffard, A. Le Moël, and N. Betz, "Physicochemical modifications induced in polymers by swift heavy ions," Nuclear Instruments and Methods in Physics Research Section B: Beam Interactions with Materials and Atoms, vol. 91, no. 1-4, pp. 140-145, 1994.

[18] A. Srivastava, V. Singh, A. Chandra, K. Witte, U. W. Scherer, and T. V. Singh, "Electrical conductivity studies of swift heavy ion modified PVC and PVC-PANI composite," Nuclear Instruments and Methods in Physics Research, Section B: Beam Interactions with Materials and Atoms, vol. 245, no. 1, pp. 277-280, 2006.

[19] A. M. Dimiev and J. M. Tour, "Mechanism of graphene oxide formation," ACS Nano, vol. 8, no. 3, pp. 3060-3068, 2014.

[20] Y. Song, K. Qu, C. Zhao, J. Ren, and X. Qu, "Graphene oxide: intrinsic peroxidase catalytic activity and its application to glucose detection," Advanced Materials, vol. 22, no. 19, pp. 22062210, 2010.

[21] M. Lv, Y. Zhang, L. Liang et al., "Effect of graphene oxide on undifferentiated and retinoic acid-differentiated SH-SY5Y cells line," Nanoscale, vol. 4, no. 13, pp. 3861-3866, 2012.

[22] S. Stankovich, D. A. Dikin, G. H. B. Dommett et al., "Graphenebased composite materials," Nature, vol. 442, no. 7100, pp. 282286, 2006.

[23] S. Pei and H.-M. Cheng, "The reduction of graphene oxide," Carbon, vol. 50, no. 9, pp. 3210-3228, 2012.

[24] V. Chandra and K. S. Kim, "Highly selective adsorption of $\mathrm{Hg}^{2+}$ by a polypyrrole-reduced graphene oxide composite," Chemical Communications, vol. 47, no. 13, pp. 3942-3944, 2011.

[25] K. Christian Kemp, V. Chandra, M. Saleh, and K. S. Kim, "Reversible $\mathrm{CO}_{2}$ adsorption by an activated nitrogen doped graphene/polyaniline material," Nanotechnology, vol. 24, no. 23, Article ID 235703, 2013.

[26] V. Chandra, S. U. Yu, S. H. Kim et al., "Highly selective $\mathrm{CO}_{2}$ capture on $\mathrm{N}$-doped carbon produced by chemical activation of polypyrrole functionalized graphene sheets," Chemical Communications, vol. 48, no. 5, pp. 735-737, 2012.

[27] N. M. Huang, H. N. Lim, C. H. Chia, M. A. Yarmo, and M. R. Muhamad, "Simple room-temperature preparation of high-yield large-area graphene oxide," International Journal of Nanomedicine, vol. 6, pp. 3443-3448, 2011.

[28] C. M. Li, C. Q. Sun, W. Chen, and L. Pan, "Electrochemical thin film deposition of polypyrrole on different substrates," Surface and Coatings Technology, vol. 198, no. 1-3, pp. 474-477, 2005.

[29] Y. S. Lim, Y. P. Tan, H. N. Lim et al., "Polypyrrole/graphene composite films synthesized via potentiostatic deposition," Journal of Applied Polymer Science, vol. 128, no. 1, pp. 224-229, 2013.
[30] D. R. Dreyer, S. Park, C. W. Bielawski, and R. S. Ruoff, "The chemistry of graphene oxide," Chemical Society Reviews, vol. 39, no. 1, pp. 228-240, 2010.

[31] A. R. Sadrolhosseini, A. S. M. Noor, K. Shameli, A. Kharazmi, N. M. Huang, and M. A. Mahdi, "Preparation of graphene oxide stabilized nickel nanoparticles with thermal effusivity properties by laser ablation method," Journal of Nanomaterials, vol. 2013, Article ID 986764, 9 pages, 2013.

[32] Y. Han, L. Hao, and X. Zhang, "Preparation and electrochemical performances of graphite oxide/polypyrrole composites," Synthetic Metals, vol. 160, no. 21-22, pp. 2336-2340, 2010.

[33] S. Jamadade, S. V. Jadhav, and V. Puri, "Electromagnetic reflection, shielding and conductivity of polypyrrole thin film electropolymerized in P-Tulensulfonic acid," Journal of NonCrystalline Solids, vol. 357, no. 3, pp. 1177-1181, 2011.

[34] Y. S. Lim, Y. P. Tan, H. N. Lim, N. M. Huang, and W. T. Tan, "Preparation and characterization of polypyrrole/graphene nanocomposite films and their electrochemical performance," Journal of Polymer Research, vol. 20, no. 6, article 156, 2013.

[35] A. Reung-U-Rai, A. Prom-Jun, W. Prissanaroon-Ouajai, and S. Ouajai, "Synthesis of highly conductive polypyrrole nanoparticles via microemulsion polymerization," Journal of Metals, Materials and Minerals, vol. 18, no. 2, pp. 27-31, 2008.

[36] J. Tauc, Amorphous and Liquid Semiconductors, Plenum Press, New York, NY, USA, 1st edition, 1974.

[37] M. M. Abdi, H. N. M. E. Mahmud, L. C. Abdullah, A. Kassim, M. Z. A. Rahman, and J. L. Y. Chyi, "Optical band gap and conductivity measurements of polypyrrole-chitosan composite thin films," Chinese Journal of Polymer Science, vol. 30, no. 1, pp. 93 100, 2012.

[38] V. Shaktawat, N. Jain, R. Saxena, N. S. Saxena, and T. P. Sharma, "Electrical conductivity and optical band gap studies of polypyrrole doped with different acids," Journal of Optoelectronics and Advanced Materials, vol. 9, no. 7, pp. 2130-2132, 2007.

[39] O. Delgado-Vasallo and E. Marin, "Application of the photoacoustic technique to the measurement of the thermal effusivity of liquids," Journal of Physics D: Applied Physics, vol. 32, no. 5, pp. 593-597, 1999.

[40] A. Rosencwaig and A. Gersho, "Theory of the photoacoustic effect with solids," Journal of Applied Physics, vol. 47, no. 1, pp. 64-69, 1976.

[41] J. C. de Lima, M. Schmitt, T. A. Grandi et al., "Structural and photoacoustic studies of mechanically alloyed $\mathrm{Ga}_{40} \mathrm{Sb}_{38} \mathrm{Se}_{22}$ powder," Journal of Physics: Condensed Matter, vol. 19, no. 18, Article ID 186216, 2007. 

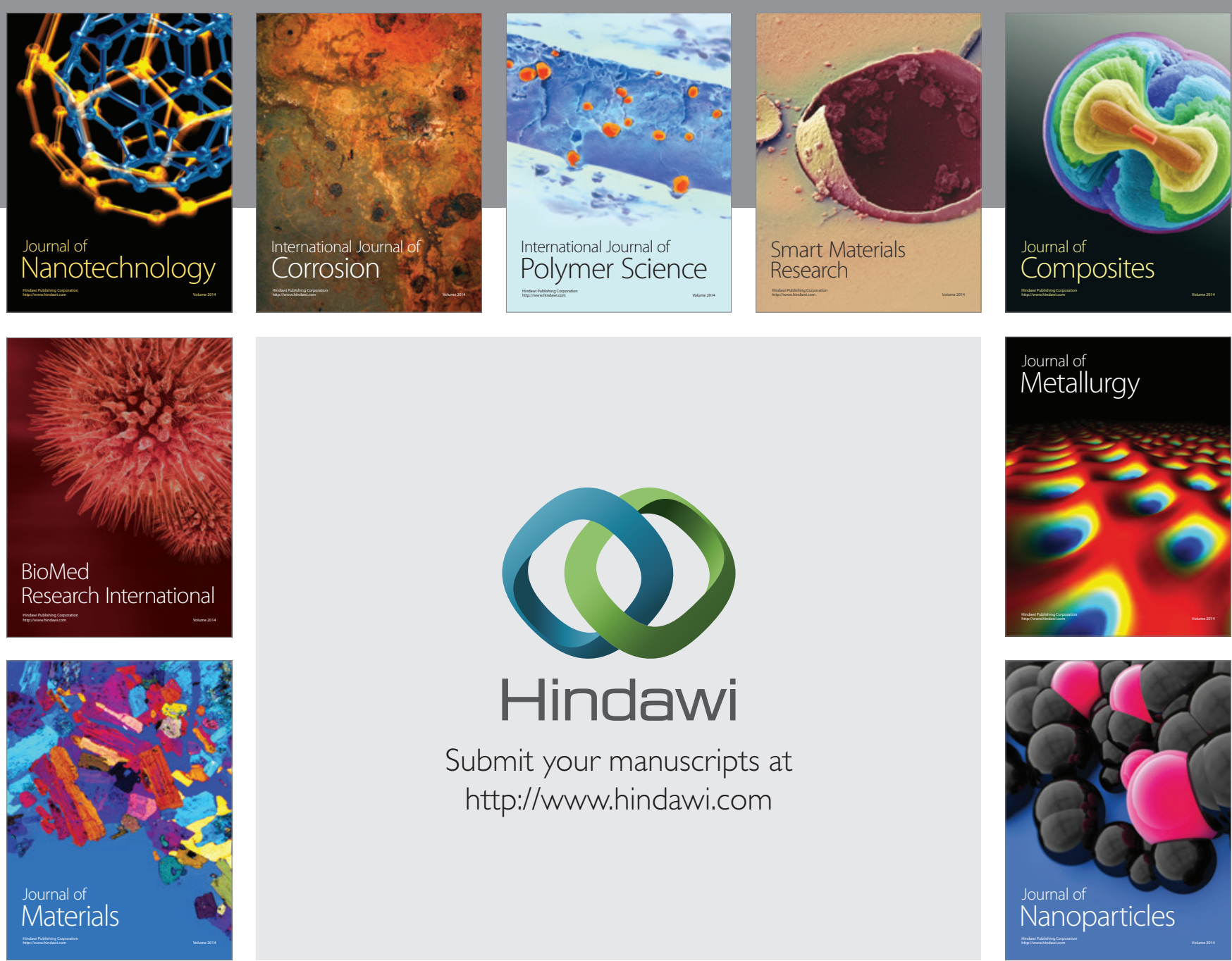

\section{Hindawi}

Submit your manuscripts at

http://www.hindawi.com

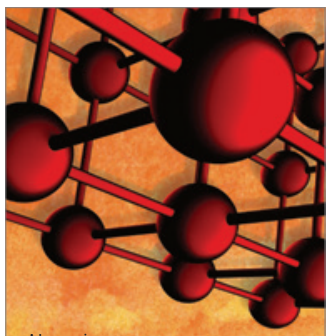

Materials Science and Engineering
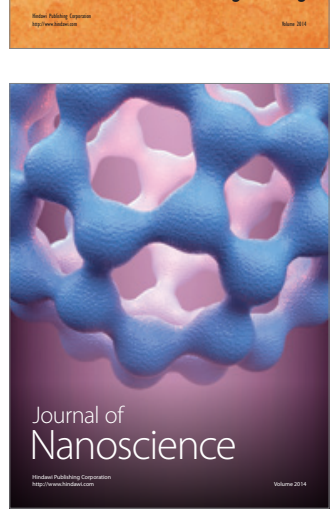
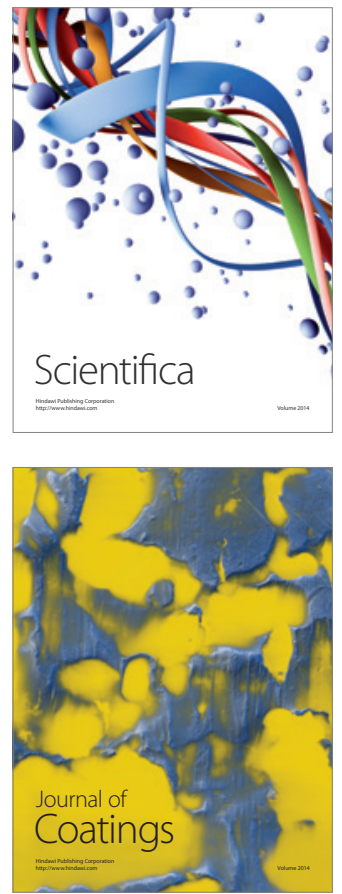
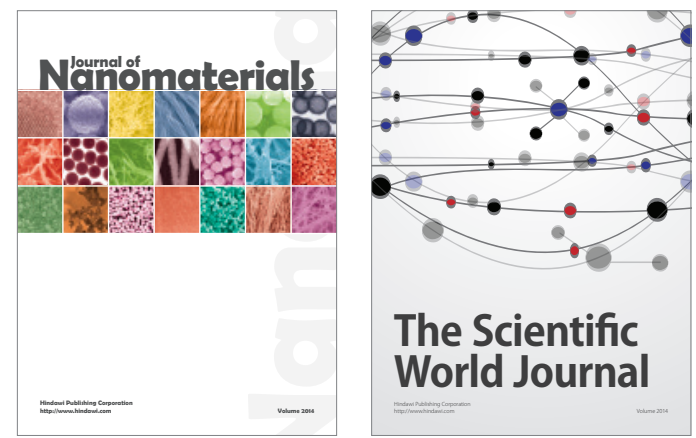

The Scientific World Journal
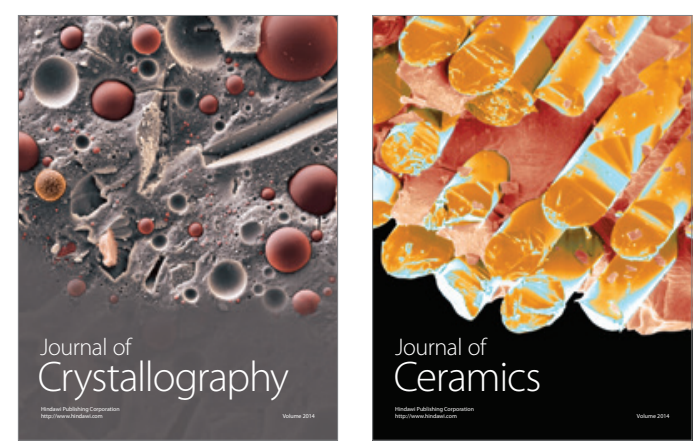
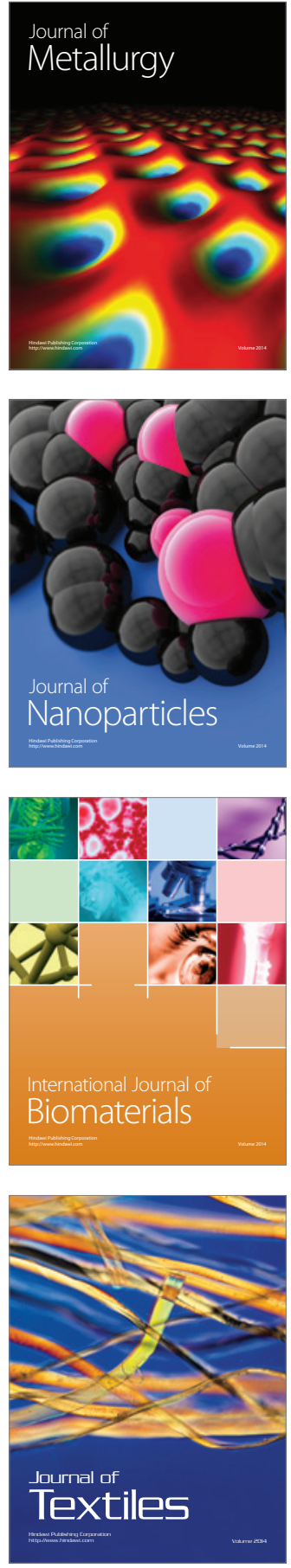